\title{
Prevalence and risk factors of pressure ulcer in hospitalized adult patients; a single center study from Ethiopia
}

\author{
Dinkie Tadele Bereded ${ }^{1}$, Mohammed Hassen Salih ${ }^{2^{*}}$ and Abebaw Eredie Abebe ${ }^{2}$
}

\begin{abstract}
Objective: The main objective of this study was to assess the prevalence of pressure ulcer and its risk factors among adult hospitalized patients at Dessie Referral Hospital, Northeast Ethiopia, 2016 G.C

Result: A cross-sectional institutional based study with a single population proportion formula was used to determine the sample size. The total sample size of 355 patients was distributed proportionally to the respected wards. Every other patient was selected by systematic random sampling technique from each ward with a response rate of $100 \%$ A total of 53 patients with pressure ulcer were detected giving the prevalence rate of $14.9 \%$. The lack of regular positioning and activity, friction/shear, and prolonged hospitalization were risk factors for pressure ulcer.
\end{abstract}

Keywords: Pressure ulcer, Prevalence, Braden scale, Patient, Cross-sectional

\section{Introduction}

Pressure ulcer (PU) also called bed sore is an area of localized damage to the skin and underlying tissue caused by pressure, shear, friction or a combination of these $[1,2]$. PU ranges from areas of slightly discolored skin to area of deep purulent wound cavities that extend to underlying muscle and bone [3]. The amount of time it takes for PU to develop varies from as short as $2 \mathrm{~h}$ in patients at greatest risk. PU is a major cause of morbidity and mortality and one of the important measures of the quality of clinical care in a healthcare setting [4-6].

PU remains one of the major health problems around the world. For every 1,000,000 patients who developed PU 65,000 die from complications which presents a major health challenge worldwide [7,8]. And also an $80 \%$ increase in the number of patients who were hospitalized from the year 1993 to 2006, which leads to PU occurrence [8].

As studies revealed, PU is common in high and middle-income countries but it is rarely researched

\footnotetext{
*Correspondence: muhenet@gmail.com

${ }^{2}$ School of Nursing, College of Medicine \& Health Sciences, University of Gondar, Gondar, Ethiopia

Full list of author information is available at the end of the article
}

in low-income countries A prevalence of $12.7 \%$ was reported in Brazil [9], 10.4\% in Turkey [10], a higher prevalence of $47.6 \%$ in Thailand [11], and $16 \%$ in Ethiopia [12]. Also, studies on health professional knowledge about pressure ulcer in Uganda and Ethiopia [13, 14].

Moreover, researchers identified variety of factors that influence the occurrence of PU including friction/shear, moisture sensory perception, immobility, the position of the patient, length of hospital stay (LHS), gender, nutritional status of the patient, age and use of medical relieving devices [12, 15-18].

Therefore, assessing the prevalence and identifying the risk factors that influence the occurrence of PUs in resource-limited countries is important for possible interventions in the prevention of PU and increases the quality of care.

\section{Main text \\ Methods \\ Institution-based cross-sectional study was conducted in Dessie Referral Hospital, Northeast Ethiopia, from March to April 2016. This hospital has different wards. Among these Medical, Surgical, Gynecological, and Orthopedic wards were selected for this study.}


All adult admitted patients and avail during the study period were the source and study population respectively. Patients who didn't develop PU prior to admission and who stayed in the hospital $\geq 24$ h were included but those patients who are critically ill were excluded from the study.

PU was the outcome) variable and sociodemographic variables, Braden risk assessment tool, clinical characteristics (like presence and type of chronic illness) and presence of medical relieving device were used for the independent variable.

The sample size was determined by using a single population proportion formula considering the following assumptions: prevalence (p) of pressure ulcer $16 \%$ taken from a recent study conducted in Ethiopia [12]. $\mathrm{Z}=$ standard normal distribution value at $95 \%$ confidence level of $Z^{\mathrm{a} / 2}=1.96$, and margin of error $(w)=5 \%$. This gave a sample size of 323 admitted patients. Considering $10 \%$ nonresponse rate, the total sample size was 355 .

Systematic random sampling technique was used to select every other patient and the first patient was selected by using lottery method.

Structured questionnaires which were developed by searching different scholars and a previous research paper on a similar study. And also physical examination to assess the presence or absence of PU and risk assessment by using checklist adapted from the Braden scale was used to collect data $[8,9]$.

The questionnaire was transcribed into Amharic (local language) by language experts and translated back to English by another language expert for consistency. Also, physical examination performed to assess and grade PU. Four B.Sc. nurses were used to collect data and two-second degree nurses assigned for supervision. Five-day training was given for both data collectors and supervisors. Data entry was done by using EPI Info version 7 statistical software and exported to SPSS version 20.0 software package for analysis.

Data quality was controlled by pre-testing the questionnaire on 36 admitted adult patients in another hospital (Borumeda) with the same setting. The presence of the association between outcome and independent variables was assessed using odds ratio (OR) with 95\% confidence interval by binary logistic regression model. Those variables having $p$ value $\leq 0.2$ in binary logistic regression model were entered into the multivariate analysis using forward ward likelihood ratio method. The final result was interpreted based upon their association of significance i.e. $\mathrm{p} \leq 0.05$.

\section{Results}

Socio-demographic and clinical characteristics of the patient A total of 355 admitted patients with a response rate of $100 \%$ were included in this study. More than half of them were rural residents. The majority $(52.1 \%)$ of the respondents were females. The mean ( \pm standard deviation) age of the respondents was $37.2( \pm 13.7)$ and the majority $(43.7 \%)$ of them fall in the age range of $33-54$. Most of the patients (65.1\%) were married. About $31 \%$ of the patients were unable to read and write. $28.2 \%$ of them had a chronic illness and from this, $32.4 \%$ were diabetic (Table 1).

\section{Prevalence and stages of pressure ulcer}

A total of $53 \mathrm{PU}$ was detected, with the prevalence rate of $14.9 \%$ (11.2-18.9). The prevalence was higher among male respondents and the sacral anatomical site was the main one. Based on the European Pressure Ulcer Advisory Panel (EPUAP) grading scale 34 (64\%) developed stage I PU (Table 1).

\section{Braden scale pressure ulcer risk assessment characteristics of adult patients}

Hundred sixty-six (46.8\%) of the respondents had no impairment in their sensory perception and 168 (47.3\%) walked frequently in their activity. Regarding mobility, 151 (42.2\%) of patients had no limitation. Of the total admitted patients $205(57.7 \%)$ were rarely moist, twothirds $(60.6 \%)$ of them had no apparent problem in their friction/shear and one-third (31.3\%) of them had probably inadequate nutrition (Table 2).

\section{Factors associated with the occurrence of pressure ulcer}

All independent variables were analyzed in binary logistic regression with the dependent variable to know their association. Among those variable LHS, the presence of chronic illness, use of medical devices, use of pressure relieving devices, position change, sensory perception, moisture, activity, mobility, friction/shear were found to be significant in binary logistic regression and then taken into multivariate analysis.

Those patients whose LHS was 7-20 days were 8.44 times more likely to develop PU than patients who were stayed for $\leq 6$ days, patients who had chair and bedfast in their activities were found to be 11 times more likely to develop PU than those patients who were walked frequently, patients who had a problem of friction/shear had 16.4 times more risk to develop PU than those who had no apparent problem in friction/shear and patient's position change also the other independent variable which was found to be associated with the PU. Those patients 
Table 1 Socio-demographic and clinical characteristics of adult patients who were admitted at DRH, Northeast Ethiopia, 2016 G.C ( $N=355)$

\begin{tabular}{|c|c|c|}
\hline Variables & Frequency & Percent \\
\hline \multicolumn{3}{|l|}{ Age (in years) } \\
\hline $18-32$ & 146 & 41.2 \\
\hline $33-54$ & 156 & 43.9 \\
\hline$>54$ & 53 & 14.9 \\
\hline \multicolumn{3}{|l|}{ Sex } \\
\hline Male & 170 & 47.9 \\
\hline Female & 185 & 52.1 \\
\hline \multicolumn{3}{|l|}{ Place of residence } \\
\hline Urban & 167 & 47 \\
\hline Rural & 188 & 53 \\
\hline \multicolumn{3}{|l|}{ Marital status } \\
\hline Single & 73 & 20.6 \\
\hline Married & 231 & 65.1 \\
\hline Divorced & 32 & 9 \\
\hline Widowed & 19 & 5.4 \\
\hline \multicolumn{3}{|l|}{ Educational status } \\
\hline Illiterate & 110 & 31 \\
\hline Read and write & 56 & 15.8 \\
\hline $1-4$ grade & 34 & 9.6 \\
\hline $5-8$ grade & 56 & 15.8 \\
\hline 9-10 grade & 58 & 16.3 \\
\hline$>10$ grade & 41 & 11.3 \\
\hline \multicolumn{3}{|l|}{ Presence of chronic illness } \\
\hline Yes & 100 & 28.2 \\
\hline No & 255 & 71.8 \\
\hline \multicolumn{3}{|l|}{ Types of chronic disease } \\
\hline Diabetes mellitus & 33 & 32.4 \\
\hline Cardio vascular disease & 25 & 24.5 \\
\hline Respiratory disease & 12 & 11.8 \\
\hline Hypertension & 14 & 13.7 \\
\hline Others & 18 & 17.6 \\
\hline \multicolumn{3}{|l|}{ Presence of pressure ulcer } \\
\hline Yes & 53 & 17.5 \\
\hline No & 302 & 82.5 \\
\hline \multicolumn{3}{|l|}{ Stage of pressure ulcer } \\
\hline Stage 1 & 34 & 64 \\
\hline Stage 2 & 16 & 30 \\
\hline Stage 3 & 3 & 6 \\
\hline \multicolumn{3}{|l|}{ Anatomical site } \\
\hline Sacral & 26 & 49.1 \\
\hline Heel & 12 & 22.6 \\
\hline Elbow & 4 & 7.5 \\
\hline Occiput & 2 & 3.8 \\
\hline Shoulder & 2 & 3.8 \\
\hline Sacral and shoulder & 3 & 5.7 \\
\hline More than two sites & 4 & 7.5 \\
\hline
\end{tabular}

DRH Dessie Referral Hospital, GC Gregorian calender
Table 2 Braden scale pressure ulcer risk assessment characteristics of respondents who were admitted at DRH, Northeast Ethiopia, 2016 G.C ( $N=355)$

\begin{tabular}{|c|c|c|c|}
\hline Variables & Frequency & Percent & Remark \\
\hline \multicolumn{4}{|l|}{ Sensory perception } \\
\hline Completely limited & 74 & 20.8 & \\
\hline Very limited & 61 & 17.2 & \\
\hline Slightly limited & 54 & 15.2 & \\
\hline No impairment & 166 & 46.8 & \\
\hline \multicolumn{4}{|l|}{ Moisture } \\
\hline Constantly moist & 48 & 13.5 & \\
\hline Very moist & 38 & 10.7 & \\
\hline Occasionally moist & 64 & 18 & \\
\hline Rarely moist & 205 & 57.7 & \\
\hline \multicolumn{4}{|l|}{ Activity } \\
\hline Bedfast & 60 & 16.9 & \\
\hline Chair fast & 40 & 11.3 & \\
\hline Walks occasionally & 87 & 24.5 & \\
\hline Walks frequently & 168 & 47.3 & \\
\hline \multicolumn{4}{|l|}{ Mobility } \\
\hline Completely immobile & 66 & 18.6 & \\
\hline Very limited & 42 & 11.8 & \\
\hline Slightly limited & 96 & 27 & \\
\hline No limitation & 151 & 42.2 & \\
\hline \multicolumn{4}{|l|}{ Nutrition } \\
\hline Very poor & 59 & 16.6 & \\
\hline Probably inadequate & 111 & 31.3 & \\
\hline Adequate & 142 & 40 & \\
\hline Excellent & 43 & 12.1 & \\
\hline \multicolumn{4}{|l|}{ Friction and shear } \\
\hline Problem & 59 & 16.6 & \\
\hline Potential problem & 81 & 22.8 & \\
\hline No apparent problem & 215 & 60.6 & \\
\hline
\end{tabular}

DRH Dessie Referral Hospital, GC Gregorian calendar

who were not changed their position had 10.42 times higher risk to develop PU than those who changed their position every $2-3 \mathrm{~h}$.

\section{Discussion}

The prevalence of PU in this study was in line with studies conducted in Ethiopia (16\%) [12], Germany 11.7\% [19], Brazil (12.7\%) [9], Turkey (11.7\%) [10]. However, higher than international survey [20]. The possible explanation for this difference (higher prevalence rate) might be due to lack of advanced nursing facility and materials in the hospital, absence of risk assessment tool, lack of guideline for prevention and treatment of pressure ulcer which leads to poorly assessing the risks. 
Table 3 Association between some selected variables and pressure ulcer at DRH, Northeast Ethiopia, $2016 \mathrm{G} . \mathrm{C}$ ( $\mathrm{N}=355$ )

\begin{tabular}{|c|c|c|c|c|c|}
\hline \multirow[t]{2}{*}{ Variable } & \multicolumn{2}{|c|}{ Pressure ulcer } & \multirow[t]{2}{*}{ COR $(95 \% \mathrm{Cl})$} & \multirow[t]{2}{*}{ AOR $(95 \% \mathrm{Cl})$} & \multirow[t]{2}{*}{ Remark } \\
\hline & No & Yes & & & \\
\hline \multicolumn{6}{|l|}{ Length of stay (days) } \\
\hline$\leq 6$ & $145(96.7 \%)$ & $5(3.3 \%)$ & 1 & 1 & \\
\hline $7-20$ & $143(82.7 \%)$ & $30(17.3 \%)$ & $6.1(2.3,16)^{*}$ & $8.44(2.1,34)^{* *}$ & \\
\hline$\geq 21$ & $8(33.3 \%)$ & $16(66.7 \%)$ & $58(16.9,198)^{*}$ & $7(10,52)^{* *}$ & \\
\hline \multicolumn{6}{|l|}{ Pressure relieving device } \\
\hline Yes & 49 (96.1\%) & $2(3.9 \%)$ & 1 & & \\
\hline No & $253(83.2 \%)$ & $51(16.8 \%)$ & $4.94(1.16,20)$ & & \\
\hline \multicolumn{6}{|l|}{ Use of medical device } \\
\hline Yes & 78 (75.5\%) & $25(24.3 \%)$ & $2.6(1.4,4.66)$ & & \\
\hline No & $229(88.9 \%)$ & $28(11.1 \%)$ & 1 & & \\
\hline \multicolumn{6}{|l|}{ Chronic illness } \\
\hline Yes & $72(72 \%)$ & $28(28 \%)$ & $3.58(1.4,4.66)^{*}$ & $2.66(0.78,9)$ & \\
\hline No & $230(90.2 \%)$ & $25(9.8 \%)$ & 1 & & \\
\hline \multicolumn{6}{|l|}{ Change position } \\
\hline Yes & $203(97.1 \%)$ & $6(2.9 \%)$ & 1 & 1 & \\
\hline No & $99(67.8 \%)$ & $47(32.2 \%)$ & $16(6.64,38.8)^{*}$ & $10.42(2.9,37)^{* *}$ & \\
\hline \multicolumn{6}{|l|}{ Sensory perception } \\
\hline Completely limited & $49(66.2 \%)$ & $25(33.8 \%)$ & $27.7(8,95.7)$ & $1.85(0.35,9.8)$ & \\
\hline Very limited & $40(65.6 \%)$ & $21(34.4 \%)$ & $28.5(8,100)$ & $1.57(0.24,10.4)$ & \\
\hline Slightly limited & $50(92.6 \%)$ & $4(7.4 \%)$ & $4.4(0.94,20.8)$ & $0.63(0.47,8.25)$ & \\
\hline No impairment & $163(98.2 \%)$ & $3(1.8 \%)$ & 1 & 1 & \\
\hline \multicolumn{6}{|l|}{ Moisture } \\
\hline Constantly moist & $25(52.2 \%)$ & $23(47.8 \%)$ & $22.6(9.16,56)$ & $2.81(0.55,15)$ & \\
\hline Very moist & $21(56.8 \%)$ & $17(44.7 \%)$ & $19.9(7.7,51.7)$ & $4.5(0.82,25)$ & \\
\hline Occasionally moist & 59 (96.1\%) & $5(7.8 \%)$ & $2.12(0.66,6.6)$ & $0.7(0.09,5.3)$ & \\
\hline Rarely moist & $197(95.6 \%)$ & $8(3.9 \%)$ & 1 & 1 & \\
\hline \multicolumn{6}{|l|}{ Activity } \\
\hline Bed fast & $28(46.7 \%)$ & $32(53.3 \%)$ & $26.28(10.6,65)^{*}$ & $7.58(1.7,32)^{* *}$ & \\
\hline Chair fast & $28(70 \%)$ & $12(30 \%)$ & $9.86(3.6,27.2)^{*}$ & $11(2,61)^{* *}$ & \\
\hline Walks occasionally & 85 (97.7\%) & $2(2.3 \%)$ & $0.54(0.11,2.66)^{*}$ & $0.42(0.043,4.1)$ & \\
\hline Walks frequently & 161 (995.6\%) & $7(4.2 \%)$ & 1 & 1 & \\
\hline \multicolumn{6}{|l|}{ Friction/shear } \\
\hline Problem & $17(28.8 \%)$ & $42(7127 \%$ & $86.06(32,231)$ & $16.4(4.4,61)^{* *}$ & \\
\hline Potential problem & $76(93.8 \%)$ & $5(6.2 \%)$ & $2.29(0.68,7.7)$ & $11(0.2,5.6)$ & \\
\hline No apparent problem & $209(97.2 \%)$ & $6(2.8 \%)$ & 1 & 1 & \\
\hline
\end{tabular}

The main objective of this study was to assess the prevalence of pressure ulcer and its risk factors among adult hospitalized patients at Dessie Referral Hospital Northeast Ethiopia, 2016 G.C Hospital

Strongly associated variables are in italic

COR crude odd ratio, AOR adjusted odd ratio, DRH Dessie Referral, GC Gregorian calendar

** $\mathrm{p}$-value $\leq 0.05,{ }^{*} \mathrm{p}$-value $\leq 0.20$ in binary logistic regression

The prevalence is lower than the study conducted in Sweden (22.9\%), Italy (27\%), Australia (22\%) and Thailand (47.6\%) [11, 21-23].

LHS in this study significantly associated with PU. Patients whose LHS was 7-20 days were 8.44 times more likely to develop PU than those patients who were stayed for $\leq 06$ days. This finding is consistent with studies conducted in Ethiopia and Sweden [12, 24]. When patients LHS increases, the risk of hospital-acquired infection increases which leads to the development of PU.

Activity is significantly associated with PU. Patients who had activity restriction (to chair and bed) were 11 times and 7.58 times respectively more likely to develop 
PU than those patients who walked frequently. This result is in line with the study conducted by Australian medical association [25]. The possible explanation for this might be due to the prolonged pressure on bony prominence which interferes circulation to the underlying skin and which in turn decreases the skin resistance to pressure (Table 3).

The odds of developing $\mathrm{Pu}$ among patients who had a problem of friction/shear was 16.4 times more likely than those who had no apparent problem in friction/shear. This finding is in line with the study conducted In Northwest Ethiopia and Thailand $[11,12]$.

Patient's position change was also the other independent variable which was significantly associated with PU. Those patients who did not have their position changed were 10.42 times more likely to develop PU than those who had their position changed every $2-3 \mathrm{~h}$. This finding was comparable with the result by an International review of PU prevention [26].

\section{Conclusion and recommendation}

The prevalence of PU was high. LHS, activity, friction/ shear, and changed position were significantly associated. We recommend for the Ministry of Health to establish a better system to early identify risk factors towards the occurrence of PU and implement different tools like Braden scale pressure ulcer risk assessment tool and prepare guideline on how to handle patients on PU. For healthcare provider's contribution is vital in the prevention of PU for admitted patients. Therefore, it would better to strive for standards of care in the health care system. Also, for researchers conducting a prospective study to examine the incidence and associated factors of PU for hospitalized patients.

\section{Limitation}

Firstly, the cross-sectional design of this study limits our ability to make causal inferences. Second, time and resource limitation for not doing a prospective study. Thirdly, a patient who already developed a PU was not grouped on their disease type.

\section{Abbreviations}

AOR: adjusted odds ratio; COR: crude odd ratio; DRH: Dessie Referral Hospital; EPUAP: European Pressure Ulcer Advisory Panel; GC: Gregorian calendar; HAPU: hospital-acquired pressure ulcers; LHS: length of hospital stay; MW: medical ward; NPUAP: National Pressure Ulcer Advisory Panel; OR: odds ratio; PU: pressure ulcer; SW: surgical ward.

\section{Authors' contributions}

MHS and DTB wrote the proposal, participated in data collection, analyzed the data and drafted the paper. AEA approved the proposal with revision; participated in data analysis and revised subsequent drafts of the paper. All authors read and approved the final manuscript.

\section{Author details}

${ }^{1}$ Dessie Health Science College, Dessie, Ethiopia. ${ }^{2}$ School of Nursing, College of Medicine \& Health Sciences, University of Gondar, Gondar, Ethiopia.

\section{Acknowledgements}

We would like to express our deepest gratitude to the University of Gondar for the approval of the ethical clearance and Amhara region health bureau for support to attend this study. We would also like to thank all patient who participated in this study for their commitment to responding to our questionnaire.

\section{Competing interests}

The authors declare that they have no competing interests.

\section{Availability of data and materials}

The data and materials used in this study are available from the corresponding author on reasonable request.

\section{Consent for publication}

University of Gondar school of Nursing ethical review committee approve for publication.

\section{Declaration}

We declare this is an original thesis. For any comment for the manuscript will be accepted on Mohammed Hassen email address (muhenet@gmail. com). Because of not identifying images or other personal or clinical details of participants that compromise anonymity, consent for publication was not applicable.

\section{Ethics approval and consent to participate}

Ethical clearance was obtained from the School of Nursing, University of Gondar. An official letter of cooperation was delivered to the administrations of the hospital. Study participants were given information about the fact that they have full right not to participate in the study if they were not willing. Also, verbal consent was obtained from each patient and approved by the School of Nursing ethical review committee before data collection. To ensure confidentiality anonymity was explained clearly to participants. Nursing care was given to those patients who have developed a pressure ulcer during the study period.

\section{Funding}

There is no funding for this research.

\section{Publisher's Note}

Springer Nature remains neutral with regard to jurisdictional claims in published maps and institutional affiliations.

Received: 31 August 2018 Accepted: 23 November 2018

Published online: 29 November 2018

References

1. Ceelen K. Aetiology of pressure ulcers A literature review. Part I of MSc-thesis, Eindhoven university of Technology, Faculty of Biomedical Engineering. 2003.

2. Keller BPJA, Wille J, van Ramshorst B, Wvd C. Pressure ulcers in intensive care patients: a review of risks and prevention. Intensive Care Med. 2002;28:1379-88.

3. Panel EPUA. National Pressure Ulcer Advisory Panel. Prevention and treatment of pressure ulcers: guick reference guide Washington DC National Pressure Ulcer Advisory Panel; 2009.

4. Benbow M. Guidelines for the prevention and treatment of pressure ulcers. Nurs Stand (through 2013). 2006;20(52):42.

5. Berlowitz D. Incidence and prevalence of pressure ulcers. In: Jini J, editor. Pressure ulcers in the aging population. New York: Springer; 2014. p. 19-26.

6. Bluestein $D$, Javaheri A. Pressure ulcers: prevention, evaluation, and management. Am Fam Physician. 2008;78(10). 
7. Macgregor L. International guidelines. Pressure ulcer prevention: prevalence and incidence in context. A consensus document. London: MEP Ltd.; 2009.

8. Soban LM, Hempel S, Munjas BA, Miles J, Rubenstein LV. Preventing pressure ulcers in hospitals: a systematic review of nurse-focused quality improvement interventions. Jt Comm J Qual Patient Saf. 2011;37(6):245.

9. Chacon JMF, Blanes L, Hochman B, Ferreira LM. Prevalence of pressure ulcers among the elderly living in long-stay institutions in São Paulo. Sao Paulo Med J. 2009:127(4):211-5.

10. Inan DG, Öztunç G. Pressure ulcer prevalence in Turkey: a sample from a university hospital. J Wound Ostomy Continence Nurs. 2012;39(4):409-13.

11. Suttipong C, Sindhu S. Predicting factors of pressure ulcers in older Thai stroke patients living in urban communities. J Clin Nurs. 2012;21(3-4):372-9.

12. Gedamu H, Hailu M, Amano A. Prevalence and associated factors of pressure ulcer among hospitalized patients at Felegehiwot referral hospital, Bahir Dar, Ethiopia. Adv Nurs. 2014;2014:1-8.

13. Mwebaza I, Katende G, Groves S, Nankumbi J. Nurses'knowledge, practices, and barriers in care of patients with pressure ulcers in a Ugandan teaching hospital. Nurs Res Pract. 2014;2014:1-6.

14. Dilie A, Mengistu D. Assessment of nurses' knowledge, attitude, and perceived barriers to expressed pressure ulcer prevention practice in Addis Ababa government hospitals, Addis Ababa, Ethiopia, 2015. Adv Nurs. 2015;2015:1-11

15. Nuru N, Zewdu F, Amsalu S, Mehretie Y. Knowledge and practice of nurses towards prevention of pressure ulcer and associated factors in Gondar University Hospital, Northwest Ethiopia. BMC Nurs. 2015;14:34.
16. Saunders LL, Krause JS, Peters BA, Karla S, Reed M. The relationship of pressure ulcers, race, and socioeconomic conditions after spinal cord injury. J Spinal Cord Med. 2016;33(4):387-95.

17. Defloor T. The risk of pressure sores: a conceptual scheme. J Clin Nurs Res Pract. 1999:8:206-16.

18. Bergstrom N. The Braden Scale for predicting pressure sore risk. Nurs Res. 1987;36(4):205-10.

19. Lahmann NA, Halfens RJ, Dassen T. Prevalence of pressure ulcers in Germany. J Clin Nurs. 2005;14(2):165-72.

20. Catherine VanGilder M, Amlung S, Harrison P, Meyer S. Results of the 2008-2009 International Pressure Ulcer Prevalence ${ }^{\mathrm{TM}}$ Survey and a 3-year, acute care, unit-specific analysis. Ostomy Wound Manag. 2009;55:39-45.

21. Gunningberg L, Stotts NA. Tracking quality over time: what do pressure ulcer data show? Int J Qual Health Care. 2008;20(4):246-53.

22. Capon A, Pavoni N, Mastromattei A, Di Lallo D. Pressure ulcer risk in long-term units: prevalence and associated factors. J Adv Nurs. 2007;58(3):263-72.

23. Prentice JL, Stacey M, Lewin G. An Australian model for conducting pressure ulcer prevalence surveys. Prim Intent: Aust J Wound Manag. 2003;11(2):87-109.

24. Gunningberg L, Stotts NA, Idvall E. Hospital-acquired pressure ulcers in two Swedish County Councils: cross-sectional data as the foundation for future quality improvement. Int Wound J. 2011;8(5):465-73.

25. Woodward M. Risk factors for pressure ulcers-can they withstand the pressure? Prim Intent. 1999;7:52-62

26. International review. Pressure ulcer prevention: pressure, shear, friction and microclimate in context. A consensus document. London; 2010.
Ready to submit your research? Choose BMC and benefit from:

- fast, convenient online submission

- thorough peer review by experienced researchers in your field

- rapid publication on acceptance

- support for research data, including large and complex data types

- gold Open Access which fosters wider collaboration and increased citations

- maximum visibility for your research: over 100M website views per year

At BMC, research is always in progress.

Learn more biomedcentral.com/submissions 